\title{
MANDIBULO-FACIAL DYSOSTOSIS (TREACHER COLLINS SYNDROME)
}

\author{
BY \\ JOHN MCKENZIE and JOHN CRAIG \\ From the Departments of Anatomy and of Child Health, University of Aberdeen
}

(ReCEIVED For PUbLCATION FEBruary 3, 1955)

Mandibulo-facial dysostosis has been described with increasing frequency in recent years. Once known it is readily recognized and may be more common than is sometimes imagined.

We describe in this article a case seen in a newlyborn infant who died at the age of $2 \frac{1}{2}$ months and in whom careful dissections were made of the facial region.

The infant (A.R., 456/1954) was admitted to the Royal Aberdeen Hospital for Sick Children at the age of 2 weeks

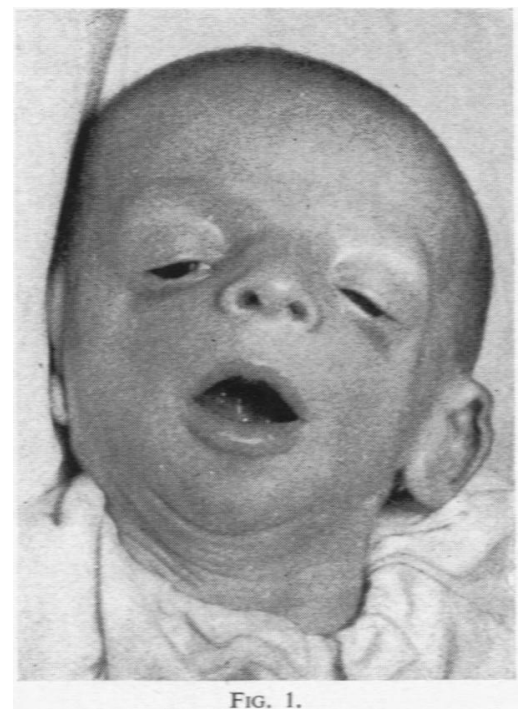

because he failed to feed easily. The infant was born of a healthy father and mother; the father had been operated on for harelip in childhood; there was a brother of 3 years who was alive and well. No history of any abnormality suggestive of dysostosis was elicited. The infant was born at full-time, weighed $5 \mathrm{lb}$. $11 \mathrm{oz}$., and breathed well after birth. He was fed from the beginning with the bottle on half-cream National dried milk. In the second week the child began to feed with difficulty.
He would take several drachms of his feed, then fall asleep; there was no vomiting and the bowels moved well. The child at 2 weeks weighed $5 \mathrm{lb}$. $7 \mathrm{oz}$.

No abnormalities were found about the heart or lungs. No masses were felt in the abdomen. On admission it was noted that the baby was a 'bird-like creature with rather curious eyes and a receding chin'; the nostrils were somewhat small; there was hypoplasia of the malar bones; the ears were rather low set with some failure of cartilage development, and appeared too big; the tongue seemed a little large and was held towards the back of

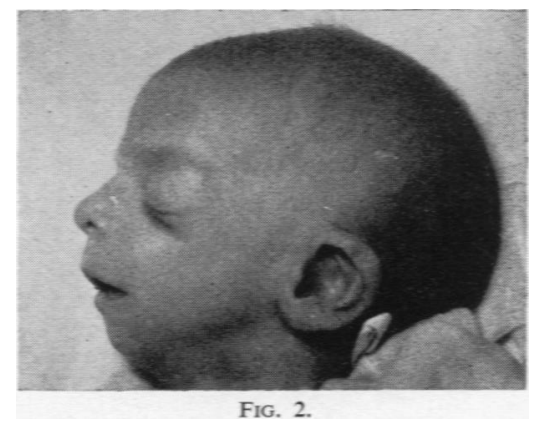

the mouth. The eyes slanted downwards at the outer ends; there was bending of the lower canthus at the junction of its inner two-thirds and outer third; the eyelashes in the upper lid and in the outer third of the lower lid were normal; they were rather scanty in the medial two-thirds of each lower lid. The appearances of the infant are seen in Figs. 1 and 2. The arms and legs moved well. The palate was high-arched. The following were the body measurements:

Head circumference $\quad$. $\quad$. $\quad$. $\quad$. $350 \mathrm{~mm}$.

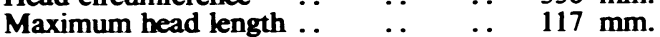

Maximum head breadth $\quad . .6100 \mathrm{~mm}$.

$\begin{array}{llllll}\text { Face length } & . & . & . & . & 54 \\ \end{array}$

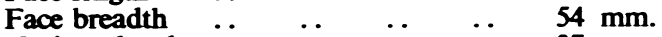

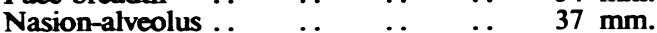

$\begin{array}{llllll}\text { Chin-occiput } & . & . & . & . & 129 \\ \text { mm. }\end{array}$

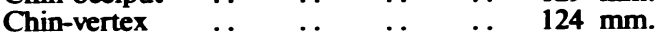

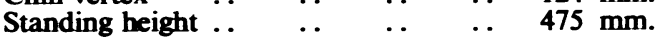


$\begin{array}{llllll}\text { Sitting height } & \ldots & \ldots & \ldots & \ldots & 350 \mathrm{~mm}\end{array}$

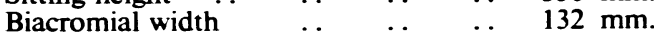
Bitrochanteric width $\quad . \quad \ldots \quad \ldots \quad \ldots \quad 83 \mathrm{~mm}$ Fontanelle A Anteroposterior $\quad \ldots .25 \mathrm{~mm}$.

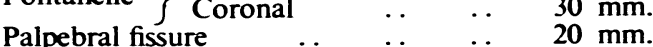

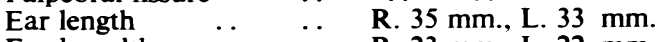
Ear breadth $\quad \ldots \quad \ldots \quad$ R. $23 \mathrm{~mm} .$, L. $22 \mathrm{~mm}$.

Radiographic examination of the skull added nothing to our knowledge of the bony state; there was poor suction of an opaque meal. The oesophagus and fundus of the stomach were normal in outline.

Feeding continued to be difficult and attempts to feed by different types of teat and by spoon were also unsuccessful, so that the infant had to be fed by catheter. The infant appeared to suck but the milk just dribbled out of the mouth. This difficulty continued for a month and then quite suddenly feeding by bottle, which had been constantly attempted, began to be successful, although some milk was constantly lost through apparent

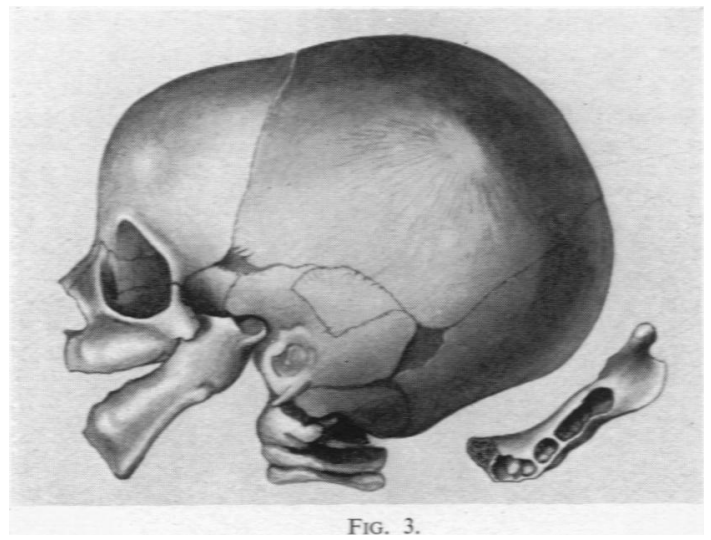

inability to swallow properly. In spite of continued attempts to keep him on a feed containing the right amount of calories, he failed to gain weight. An occasional cyanotic attack occurred, and he died at the age of 10 weeks.

A post-mortem examination showed that the body was that of a poorly nourished male child. The brain was of normal size and showed no notable external abnormality; the lungs showed extensive patchy basal collapse with a few areas of consolidation; there was no evidence of inhaled material in the trachea or main bronchi. The pericardial sac and the heart were normal; liver and spleen and intestinal tract were normal; there was no lesion in the gall bladder, pancreas, adrenals or kidneys; the ureters were patent and the bladder normal in size.

The head and neck were fully dissected. Abnormalities similar on both sides were revealed. The zygomatic bone and zygomatic process of the temporal bone were absent (Fig. 3), but the maxilla, as well as completing the margin of the orbit, also provided a postero-lateral projection for the upper attachment of the masseter. It did, however, allow the lower orbital margin to fall away laterally, thereby causing obliquity of the palpebral fissure. The squamous temporal bone was smaller than normal, the deficiency being made up by the surrounding bones and by a small extra plaque between the temporal and the parietal bones. The head of the mandible, elongated antero-posteriorly instead of transversely, was separated from a shallow articular fossa by a normal cartilaginous articular disc; there was no articular eminence; the coronoid process of the mandible was everted while the body was foreshortened and receding.

Within the middle-ear, the incus and stapes were absent, but the middle-ear cavity and internal ear were normal.

There was no parotid gland.

The musculature of the face and head was nowhere deficient; indeed, it was unusually well developed, there being many extra muscle bundles in the facio-platysmal sheet and a tendency for the individual muscles in the masticatory group to become confluent.

The maxillary artery (Fig. 4), after supplying normal

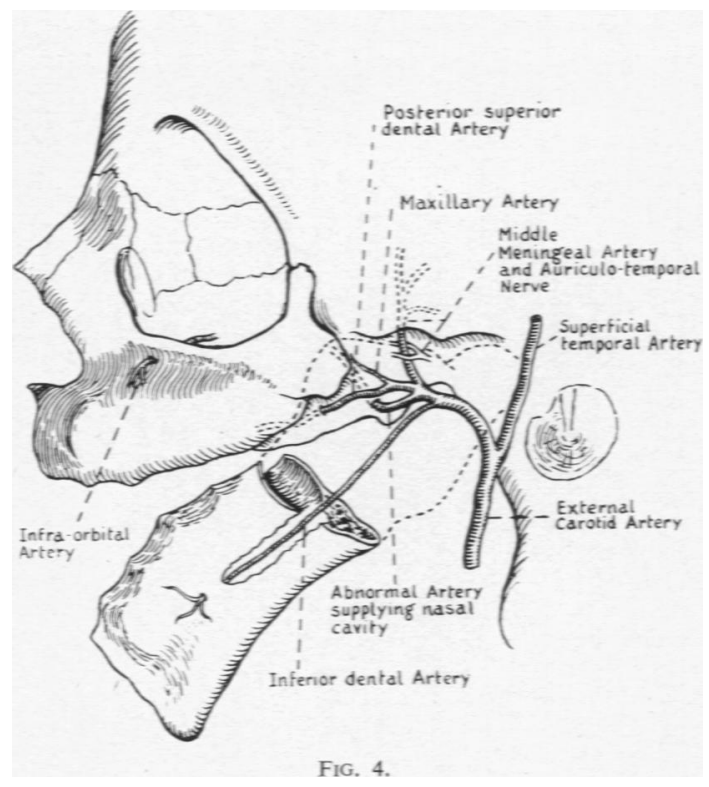

inferior dental, posterior superior dental and middle meningeal branches, petered out before it reached the pterygo-maxillary fissure. The lower surface of the palate was supplied by the posterior superior dental vessel, while the nasal cavity received blood from a vessel which arose from the maxillary artery near the origin of the inferior dental artery, ran along the lower border of the lateral pterygoid muscle, entered the pterygo-palatine fossa from behind and finally ran up to and through the sphenopalatine foramen into the nose. The infra-orbital 
artery was a branch of the ophthalmic artery. The middle meningeal artery (Figs. 4 and 5), after it entered the skull and before it divided into its two branches, produced a vessel which ran backwards and medially as if it were reaching out for the internal carotid artery, but faded out behind the mandibular nerve.

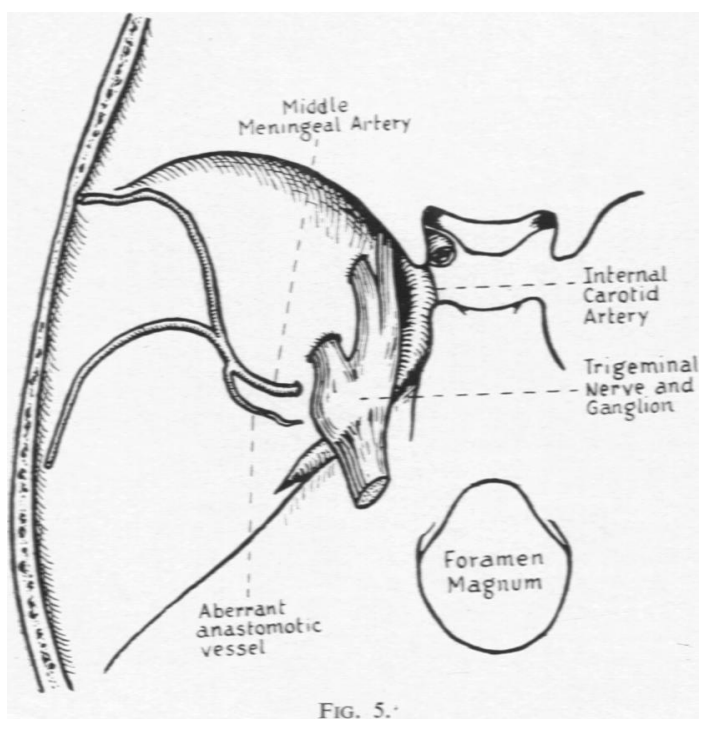

Discussion

After Treacher Collins (1900) described two cases showing notching of the lower eyelids associated with defective development of the malar bones, these features were regarded as the essential characteristics of the Treacher Collins syndrome; but it is now realized that many other features such as abnormalities of the mandible and of the ear may be safely included under this title and that the slight anti-mongoloid obliquity of the palpebral fissures, occurring alone in a patient and causing no comment whatsoever, is the minimal clinical manifestation of the same syndrome (Franceschetti and Klein, 1949). After reviewing many of the published cases and describing several others, these authors recognized, as did Mann and Kilner (1943), that the essential lesion was a hereditary maldevelopment of the maxillary process and mandibular arch, and with the data gleaned from clinical and $x$-ray examination, concluded that the cause of this congenital abnormality was 'an inhibitory process occurring towards the seventh week of the embryonic life and affecting the facial bones deriving from the first visceral arch". They assumed the aetiology to be 'a disturbance of the organization center.

Hövels (1953a), in a more extensive survey of the literature, graded the recorded cases to form a series, from the simplest form, showing only obliquity of the palpebral fissures, to the most extensive, which included deformations such as agnathia. His attempts (Hövels, 1953b) to find the cause of the abnormality were based on the work of authors such as Hörstadius (1950) who found that the visceral arches were derived in their entirety from the rostral end of the neural crest where areas could be mapped out corresponding to these derivatives. Extirpation of these areas resulted in deficiencies in or the absence of the corresponding arches. Hövels maintained that some defect in the neural crest area responsible for the first visceral arch produced the structural abnormalities of the Treacher Collins syndrome.

This theory, however, will not withstand critical examination. For example, the most frequently affected part of the face is the zygomatic bone which is the proximal part of the maxillary process; if, as Hövels suggests, it were predetermined within the neural crest that there was to be no zygomatic bone, then surely the maxillary process would not be long enough to meet and fuse with the nasal processes. Yet they do; there is no cleft palate, harelip, or interference with the naso-lacrimal duct. The observations obtained clinically and radiologically must be supplemented by the detailed anatomy of the deeper tissues in the region of the abnormality before theories as to its origin are put forward. This has been difficult because the syndrome is quite compatible with life and only occasionally can a case be thoroughly investigated. Lockhart (1929), who first dissected the abnormality, did not correlate his findings with any clinical abnormality, and consequently his article has been overlooked as a source of information on the anatomy of the syndrome. He drew attention to the association of absence of the zygoma with abnormalities in the middle ear and with minor alterations in the muscles of mastication. Even in Hövels work there is no mention of the condition having been dissected. It is obvious when the abnormalities in the arteries supplying the tissues derived from the maxillary process are considered that this portion of the first visceral arch suffered from a temporary deficiency in its blood supply by occlusion or failure of the maxillary artery at an early age. However, while the zygomatic bone had no alternative means of nourishment at the critical stage of its ossification and therefore did not develop, the maxilla borrowed a blood supply from the internal carotid artery through the ophthalmic artery to tide it over until a secondary source was available from the root of the maxillary artery.

According to Keibel and Mall (1910-12), the 
normal development of the arteries derived from the first aortic arch is as follows (Fig. 6): Three arteries are produced from the first aortic arch: (1) the supra-orbital, later to become the middle meningeal artery, (2) the infra-orbital representing the maxillary and (3) the mandibular or inferior dental. With
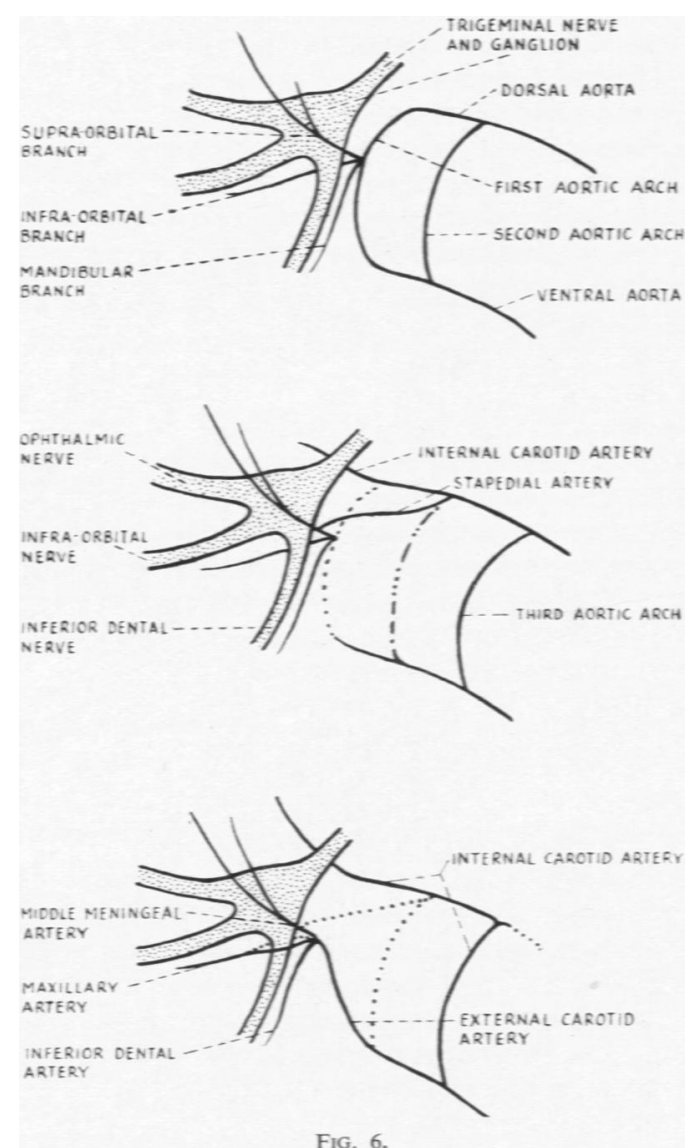

the disappearance of the first arch, these three vessels are all maintained by the stapedial artery, a shortlived vessel in the human embryo passing through the stapes, supplying the structures derived from the posterior end of the second visceral arch, and affixing itself to the stem of the supra-orbital artery. When the external carotid artery develops it takes over these three vessels again and the stapedial artery disappears. The two vessels whose absence is involved in the production of the Treacher Collins syndrome are the stapedial and infra-orbital arteries, yet according to the foregoing description there is no more reason for the infra-orbital vessel being associated with the absence of the stapedial than for either of the other two first arch vessels. Could the development of these vessels not be as shown in Fig. 7? Instead of the supra-orbital, infra-orbital and mandibular vessels arising fanwise from a single point, let them arise separately; and let the
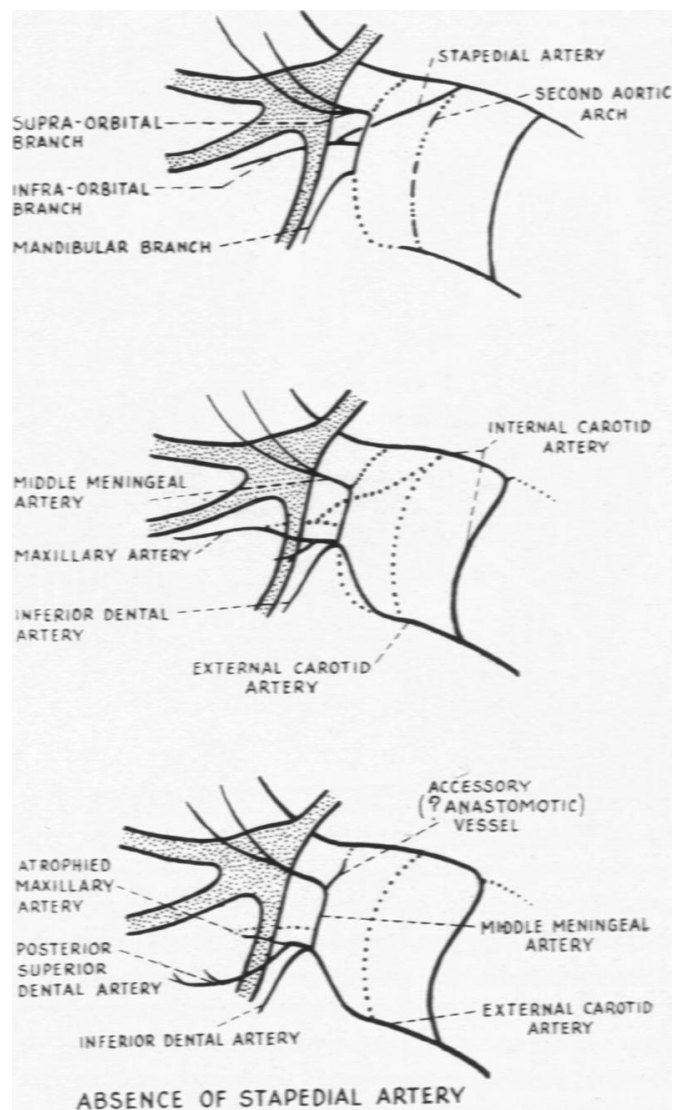

FIG. 7.

infra-orbital artery, since it originally runs deep to the mandibular nerve, be the vessel which receives the stapedial artery and depends on it to a greater extent than do the others for its survival. Without the help of the stapedial artery the middle meningeal artery could still continue to function by retaining its connexion with the dorsal aorta. This is significant when it is remembered that the specimen described here had an aberrant vessel from the middle meningeal artery which could have anastomosed with the internal carotid artery at one time round the back of the mandibular nerve. The mandibular artery could likewise survive from its 
connexion with the ventral aorta or the developing external carotid. In addition to describing what is the more probable sequence of events in the development of the vessels in this region, we can also show that there is still in the adult a remnant of the first aortic arch, namely, that part of the middle meningeal artery between its origin from the maxillary and a point near its bifurcation. That small piece of first aortic arch between the infra-orbital and mandibular arteries is transferred to the middle meningeal artery as well when the infra-orbital forms its anastomotic loop around the mandibular nerve to lie superficial to it as in the adult.

It seems, then, that the original lesion in the Treacher Collins syndrome lies with the stapedial artery; its absence will give defects of the stapes and incus and maldevelopment of the first arch vessels usually involving but not necessarily restricted to the maxillary: failure of the inferior dental to retain or find an auxillary source of supply will give concomitant abnormalities of the mandible. The possibility of a normal stapedial capable of supplying the posterior end of the second visceral arch and no more will account for the defects of bones and soft tissues being confined to the face. We can in this way account for all recorded abnormalities constituting the Treacher Collins syndrome, however severe, or however variable, and further we can point to the sixth week of intra-uterine life as being the age for the inception of the abnormality, i.e. immediately after the formation of the primitive face.

\section{Summary}

A typical case of the Treacher Collins syndrome (mandibulo-facial dysostosis) is described with the clinical features and the abnormal details of its anatomy.

A fresh suggestion regarding the cause of the abnormality is put forward, based chiefly on the arterial abnormalities present in this case, viz. that a defect of the stapedial artery causes maldevelopment not only in its own field of supply but also in the region of the first visceral arch whose vessels the stapedial artery normally supports during the critical phase between the disappearance of the first aortic arch and the full development of the external carotid artery, just after the formation of the primitive face.

The normal development of the arteries in and near the first visceral arch is reconsidered and modified.

We are indebted to Professor R. D. Lockhart for his interest and advice during the investigation, to $\mathrm{Mr}$. W. Cruickshank for the illustrations and to Mr. R. G. M. Drummond for the photographs.

\section{REFERENCES}

Collins, E. T. (1900). Trans. ophthal. Soc., 20, 190.

Franceschetti, A. and Klein, D. (1949). Acta ophthal., Kbh., 27, 143. Hôrstadius, S. (1950). The Neural Crest. London.

Hōvels, O.' (1953a). $Z$. Kinderheilk, 73, 532.

- (1953b). Ibid., 73, 568.

Lockhart, R. D. (1929). J. Anat., 63, 233.

Keibel, F. and Mall, F. P. (1910-12). Manual of Human Embryology. Philadelphia.

Mann, I. and Kilner, T. P. (1943). Brit. J. Ophthal., 27, 13. 